\title{
FISH PROCESSING BY-PRODUCTS EXPLOITATION AND INNOVATIVE FISH-BASED FOOD PRODUCTION
}

\author{
Mihails Šilovs \\ Latvia University of Life Sciences and Technologies, Latvia \\ SIA "Piejūra", Latvia \\ mihails.silovs@gmail.com
}

\begin{abstract}
In the fish processing sector, the further exploitation of by-products and wastes left after industrial production promotes sustainability of raw materials, access to added value and increased profitability, as well as contributes to environmental protection by reducing the volume of dumped products. Besides obvious value-added features, it also addresses the clear market demand dictated by prospects of the population growth. Given the limitations for further expansion of the husbandry sector, fish-based items available for human consumption represent a major avenue for coping with the pressing demands of increased population and enable the development of innovative food items of high nutritional importance. Current research is focused on the analysis of fish processing by-product utilization possibilities available up to date and introduces empirical findings of innovative food product development made on the basis of by-products left after traditional canned "Sprats in oil" production. In Latvia, "Sprats in oil" production is an integral part of fish processing sector and the rural economy overall. The production accounts for at least $30 \%$ of raw material left as by-products (smoked heads and, in some cases, tails) after such technological stage as smoked sprats processing into cans. Efforts were made to prepare value-added and attractive to customer food product made out of this fish-processing by-products, which are typically processed to a fishmeal or just dumped as waste. The study demonstrates a strong potential for its utilization to a range of fish pâté with various flavours and of high nutritious value.
\end{abstract}

Key words: fish processing by-products, fish-based pâté, smoked sprats, innovative food products, food economy.

\section{Introduction}

The problem of the integrated and rational use of raw materials continues to remain highly relevant for the seafood processing industry all over the world. The search for new technical and organizational solutions aims to make it possible to effectively utilize the proceedings that are of little use and reduced commercial value.

Demand for innovative fish and fish-based items follows an upward trend in fish processing, generating a significant amount of by-products and wastes as well as large volumes of low-value fish by-catch that are not efficiently exploited to maximize their economic potential. In 2012, over 21 million tons of fish were lost or served to non-food purposes (FAO, 2014) because of an array of undesirable characteristics, e.g. extreme heterogeneity, small size, flavour, bony structure, unacceptable appearance, substantial fat content, threat of toxic substances. As a result only 50 $60 \%$ of catch is used for human consumption and $25 \%$ directly discarded as waste (Rustad, 2003). Research indicate that up to $50-80 \%$ of raw fish material can be dumped as solid waste after processing, i.e. traditional round filleting (Wasswa, Tang, \& Gu, 2007). Shahidi \& Botta (2012) mention such major fish processing by-products and discards as edible tongue, cheeks, stomach and liver, proteins from residual fish, fish skin, chitinous materials, cartenoid pigments, flavourants, gut enzymes, and anti-freeze proteins from blood of cold-temperature fish that can be considered for further processing. In Latvia, traditionally, low-value fish and fish-processing by-products are exported as a raw material with little added value, processed into fishmeal, or considered for a uniform production (i.e. smoked sprats), thus, determining significant loss in terms of economic gains for the whole industry (Mulye et al., 2014). The exploitation of these types of fish and fish processing by-products to develop innovative products has a vast potential to add value, minimize wastage, and promote their efficient utilization.

Fish processing by-products can be transformed into various types of items such as food, pharmaceutical and biotechnology products with good market value. The consumer market has become used to the regular supply of innovative, new products, which forces producing companies to engineer new product lines and use updated processing technologies. In food sector, the contemporary research in this area is directed primary at developing new approaches for various types of fish-based minced meat and obtaining a wide range of products made on their basis, such as culinary and sausage products, delicacy product analogues, preserves and canned goods (Sharma \& Basu, 2003; Devi, Aparna, \& Kalpana, 2013).

The main difference between minced meat products and products based on the whole fish or its specific part (i.e. fillet) is the extent to which the raw materials are used. Overall, in the classic fish industry, only $30-40 \%$ of the fish are processed into high quality produce (fish steaks, medallions or fillets) and $60-70 \%$ are the fish processing low-quality and low economic potential by-products that virtually are not in demand in the food market. Moreover, the utilization of such surpluses in production is usually problematic 
and creates large financial and environmental costs. Nevertheless, fish processors are focused on extracting the most value out of primary products, with little interest in by-products resulting in missed economic opportunities because of insufficient investment in technologies that allow for the utilization of such material.

The aim of the study is to explore the exploitation options of the fish processing by-products and develop a new consumption-ready product with satisfactory organoleptic qualities ready for production and diversification. The research also aimed to indicate and address the technological challenges of sprat processing by-product exploitation as a raw material. As a result of the project, fish-based pâté parte (spreadable product) has been developed out of sprat processing by-products, while fish-based terrine (typically served in slices) is in its developmental phase. A number of variations (additives, flavours, colours) have been developed from each basic product to expand the range.

\section{Materials and Methods}

Our research focuses on Baltic sprats (Sprattus sprattus balticus), a small herring-like, marine fish found in the Baltic Sea waters and very traditional for the Latvian rural economy. The fish processing waste, i.e. the heads and, in some cases, tails, of smoked sprats (from in-house laboratory, Piejūra Ltd., Nīca, Latvia) were used to develop the pâté. The research was implemented in a period of seven months and took place from September, 2017 till March, 2018. The current research has resulted in further series of researches on the product line diversification.

The latest data from 2015, available at the Food and Agriculture Organization of the United Nations Global Capture Production database, show that marine capture production for Sprattus sprattus has significantly increased by $36.9 \%$ from 2014 to 2015 and reached 677,029 in 2015 (FAO, 2017). Despite being an integral part of Latvian and regional fish sector, Baltic sprats are considered an industrial species since the largest part of the caught gets processed into commodities not intended for human consumption, specifically, fishmeal (Miles \& Chapman, 2015). Industrial species are characterized as marine wild-caught, small, bony, and oily fish not suitable or with limited suitability for human consumption (Rustad, 2003). In Latvia, approximately, only $25 \%$ of sprats caught are processed into items for human consumption, mainly into canned sprats, usually smoked, ("Sprats in oil"). Besides, canned sprat production is very resource consuming and does not provide significant profits. Moreover, while being a traditional product in the region, the market for "Sprats in oil" is quite limited. Despite the wide export geography, the product is consumed mainly by the local population and proportionally small Eastern European expat communities abroad.

The implemented project explored the possibilities for the technology development aimed at ready-to-eat product elaboration from sprat processing by-products remaining after smoked fillets are processed further to traditional "Sprats in oil". The literature review of fish processing by-products, as well as analysis of technological potential of the pâté production out of the sprat processing by-products, explore the possibilities of innovative fish-based product exploitation in the food sector.

\section{Results and Discussion}

Fish processing by-products and their economic potential

At present, there is an established shortage of highquality animal protein in the world (Pimentel \& Pimentel, 2003). The main source of such protein livestock and husbandry - in the developed countries is approaching the saturation limits and it is difficult to predict multiple increase in productivity, despite the pressing demands of rapid urbanization and overall population growth. At the same time, industrial fishing and fish farming have great development prospects. For example, a lot of research demonstrates that sprats are a valuable source of protein, minerals, lipids, and vitamins, at the same time containing only a small amount of carbohydrates. Nonetheless, it should be acknowledged that the range of fish products is quite limited and the industry is facing the need to develop and bring to the market new products from fish, expanding the variety from the currently prevalent fresh, frozen and canned fish offerings. On the other hand, the fish product processing produces a large amount of by-products and waste with a high content of nutrients, which are denied for human consumption, for example, ridges with meat cuts and fish heads. Overall, there can be distinguished four main roads for fish processing by-products and waste utilization according to the potential added-value volume and profitability: fertilizers, feed production for aquaculture, livestock and domestic animals, food production intended for human consumption, and advanced solutions for biotechnological, pharmaceutical and similar sectors.

- Fish-based fertilizers have been used in agriculture for centuries. The approach may not even require any processing when i.e. spoiled fish is dumped on the fields to increase land fertility. The production of fertilizer from dead fish was industrialized as early as at the beginning of the 20th century, however, the profitability of this approach is quite low. Approximately $10 \%$ of fish processing byproducts and waste is used as organic fertilizer for agricultural needs.

- The next segment is fishmeal production for aquaculture and domestic mammal animals, 
mainly in the form of fish flour. Worldwide, up to $30 \%$ of total fish and shellfish catch is processed into fishmeal and oil (Bimbo \& Crowther, 1992). Meals \& Chapman (2015) indicate that approximately $90 \%$ of fishmeal is utilized in fish and animal diets, including pets, providing about $14 \%$ of the world's need for animal protein (Venugopal, Shahidi, \& Lee, 1995). In Latvia, $75 \%$ of sprats catch is utilized to satisfy the fishmeal production, a commodity of significantly lower profitability than food production intended for human consumption or advanced technological solutions (Jackson, Kerr, \& Cowley, 1984).

- Fish-based products meant for human consumption compose the two areas of fish processing providing a significantly better profitability food production and advanced solutions such as bioactive components for pharmaceutical and biotechnology sectors, including beauty industry. For instance, in comparison to mammal collagen, fish-based collagen has been much less studied despite the fact that about $30 \%$ of fish processing wastes are skin and bone with high collagen content (Wasswa, Tang, \& Gu, 2007). Nonetheless, whilst being the sector with the highest potential profitability, the high-end solution sector is the most progressive and, thus, requires significant and consistent investment as well as scientific capacity. Innovative solutions for fish processing by-product exploitation for the food sector, although, also require significant innovation and knowledge intake, are yet more available for scaling and introduction to fish processing sector of our region.

Rustad (2003) indicates that the market interest is an essential factor promoting investment and innovation fuelling improved utilization of fish processing byproducts. The market potential of innovative fishbased human consumption products, including those based on industrial species, is clearly rooted in the growing population. For instance, Parfitt, Barthel, \& Macnaughton (2010) note that by 2050 there must be found "prospects for feeding a population of nine billion”. Moreover, United Nations estimations (2008) indicate that by $205070 \%$ of the population will live in urban environments, thus, indicating steep shrink of the agricultural sector. At the same time, research demonstrates that currently, up to $50 \%$ of food does not reach the consumer (Lundqvist, de Fraiture, \& Molden, 2008; Parfitt, Barthel, \& Macnaughton, 2010). Most of the waste appears within the post-harvest phase, whereas process losses can be eliminated by introducing more advanced production methods and technologies.

These tendencies, along with the changing consumer behaviour and increased pace of the daily life, have been already indicating large market potential for ready-made consumption products. Moreover, the demand for fish-based ready-made consumption products is expected to grow. As demonstrated by Parfitt, Barthel \& Macnaughton (2010), the increasing demand for fish-based products is strongly associated with Bennet's law, indicating the decline in consumption of starchy food staples and dietary transition towards dairy, meat, fish, and fruits and vegetables as income increases. This will further increase the added value, which is demand driven and exists if the consumer wants the product and is willing to make the purchase (Salin, Atkins, \& Salame, 2003). In addition, it should be noted that there is a strong market demand to make sure food items are still affordable for lower income groups (Parfitt, Barthel, \& Macnaughton, 2010).

Thus, sprat processing by-product further exploitation in human consumption ready food item production can be considered as the best solution providing the highest potential added-value volume and profitability, whilst requiring comparatively moderate investment. At the same time, it addresses both the immediate need for additional food sources and increased consumer interest towards fish products, as well as the demand for products in a low-cost segment. It clearly offers the producers an additional income source, whilst reducing costs for processing waste disposal. Nonetheless, in such a production a number of technical challenges should be considered along with producing a sprat processing by-productbased food item with satisfactory organoleptic features, so final customers would be interested in buying it.

Innovative pâté made of smoked sprats processing byproducts ready for human consumption

Following the changing consumption behaviours, in the food industry the number of ready-to-eat foods, which do not require culinary processing and include heterogeneous components, is increasing. Examples of such products already available on the market are drinks from whey and juices, cheeses with slices of ham, hams and sausages with pieces of cheese and so on. However, in the fishing industry, the trend is not so pronounced, the number of ready-to-eat foods is small, and the situation has been changing significantly slower.

According to Gildberg (1993), by-products are all the raw materials, edible or inedible, left during the production of the main product. Traditionally marine by-products that can be considered for food production are bones, skin, viscera, and cut-offs left after fillet cut. In the production of the classic fish product canned "Sprats in oil", the by-products are fish heads and, often, tails left after fish decapitating 
from strings used for smoking. Such by-products are usually utilized or, at best, processed for fish meal, while the content of proteins and lipids allows them to be considered as raw materials for food. Indeed, our research demonstrated that these products can be used as a source for added-value human consumption item production. The production process of "Sprats in oil", requires sprat smoking after the fish is sorted, washed, and then threaded on rods through the gills. After smoking, the fish is decapitated by cutting it off the rods (the fillet is separated from the head that remains on the rods). Fillets are further used for canning, while smoked heads usually do not find use. Nonetheless, heads of sprats constitute $13-17 \%$ of the mass of fish and contain up to $55 \%$ of valuable food raw materials - proteins and lipids.

There is a number of difficulties in the further processing of smoked head of sprats, which prevents their consumption in food:

- The small size of heads, which does not allow to separate edible parts from inedible;

- A large number of solid parts (bones of the skull, gills, jaws), which cannot be chewed;

- Strong smell of smoking and a large concentration of smoking substances, exceeding concentration acceptable in food products;

- A large amount of connective tissue and an unsatisfactory amino acid score.

The research indicated the utility of the following technological operations aimed at addressing the difficulties, thus, allowing to consider the smoked heads of sprats as the food raw material:

- Thorough grinding with an aim of achieving the homogeneity of the structure. Fine grinding of fish raw materials is the main technological problem. In industrial production, well-configured highspeed cutters are to be used to finely cut fish waste, or the pâte made in a low parameter cutter is to be regarded as a semi-finished product and should be passed through the emulsifying process. In many cases, a simple cutter used in conjunction with the emulsifying is much better than an expensive high-speed cutter.

- Enrichment with a high-value protein (animal, vegetable or milk) to improve the amino acid scores.

- Use of fillers to reduce the concentration of smoking substances to those permitted for use in the food industry.

- Treatment with special substances to soften the bone tissue (if necessary). When choosing the amount of vinegar required for the decalcification of bone tissue, it should be taken into account that, on the one hand, a large amount of vinegar protects the product from spoiling and considerably softens bone tissue of the cut fish heads; on the other hand, continuous storage of the pâté in cans allows reducing the amount of vinegar, making the product flavour less spicy and acid as well as reduces the possibility that the pâté will lose its colour as a result of long-time storage.

- Use of texturates, thickeners, spices and flavours to ensure required organoleptic parameters. The TARI blend of food flavourings may be replaced by considerably cheaper mono-ingredient blends.

- The choice of the mode of sterilisation considerably depends on the autoclave equipment and working conditions at each specific enterprise as well as on a number of other factors. This question is to be considered individually together with the enterprise technologists taking into account the ingredients and microbiological analysis of the pâté.

The analysis of processing peculiarities of byproducts left after "Sprats in oil" production, led us to the conclusion that pâté is the most promising product that can be made out of smoked sprats by-products. Pâté is a finely grinded product containing a significant amount of fillers, emulsifiers and flavouring agents. In addition, pâté has been regarded as a cheap product, therefore, using low cost fish raw material such as sprats and its processing by-products have been found suitable. One of the main issues still to be resolved is identifying additives that provide for extending the shelf life, as well as ensuring the specified structure and colour without changing and maintaining certain quality indicators. At present, the biggest challenge is to achieve the lighter colours and diminish the number of E-substances in the composition.

It should be noted that given the target niche of the product using expensive ingredients should be overall avoided. Nonetheless, it should not compromise the organoleptic features of the product in order to maintain the demand. Since smoked heads have a distinct flavour and smoke aroma, the solution is to use ingredients having a distinct and spicy flavour (onion, garlic, black pepper, etc.) rather than mild spices. In order to lower the concentration of the substances generated in the process of smoking, fillers (cream of wheat, starch, soy, fibres) should be used. It is recommended adding phosphate blends to the pâté together with salt during the first stage of production to increase the water-binding capacity of fish raw materials and moisture retention. In order to get the pâté texture intended, water binders or fillers may be used. The research allowed to produce pâté with acceptable organoleptic qualities. The pâté developed during the research was scored between "average" to "good" during the evaluation process for all the attributes: colour, aroma, texture, taste, aftertaste, and appearance $(N=58)$.

On the basis of the neutrally flavoured pâté, it is possible to produce a wide range of products with 
more complicated flavours. The variety of the product has been expanded by adding flavours to obtain such pâté variations as:

- "Borodinsky" with cumin and cardamom;

- "Chilly" with red hot chili pepper flakes and grains (this pâté is coloured using the liquid paprika extract);

- "Mediterranean Herbs" - with dried rosemary and thyme;

- "Tomato" pâté containing $80 \%$ of pâté and $20 \%$ of tomato paste;

- "Classical" - it is the base pâté coloured using the "Caramel - burnt sugar" colouring.

\section{Conclusions}

- The growing population, rapid urbanisation and changing consumption behaviours create a strong market interest for innovative food products, including fish-based food products. Despite the constantly growing demand, only approximately a half of catch is used for human consumption, whilst, $25 \%$ is directly discarded as waste; up to $50-80 \%$ of raw fish material can be discarded as solid waste after processing.

- The sector with the highest potential profitability for utilisation of the fish processing by-products is food production intended for human consumption and advanced solutions for biotechnological, pharmaceutical and similar sectors. Due to associated extensive investment and scientific capacity limitations of the latter option, the food production is more promising for the fish processing industry of our region.

- The implemented project has successfully proved that fish processing by-product exploitation as a raw material for fish-based innovative food products has a significant potential. The experimental research has proved the possibility to produce food items available for human consumption (pâté, terrine) out of heads of smoked sprats, the by-products left after traditional canned "Sprats in oil" production.

- There is a number of technological difficulties associated with the processing of smoked heads of sprats, which challenge their consideration as a raw material for food production intended for human consumption, - mainly heterogeneity of the pâté structure and strong smoked aroma of the raw product. The research indicated that there are several technological operations available to address the limitations. The implementation of the technological solutions led to obtaining products with satisfactory organoleptic features approved by the final customer.

- Producing neutrally flavoured pâté allows developing an expanded range of products with more complicated flavours that are attractive for customers, thus, increasing the profitability of fishprocessing by-product exploitation.

\section{Acknowledgements}

In accordance with the contract No. 1.2.1.1/16/A/004 between "Latvian Food Competence Centre" Ltd. and the Central Finance and Contracting Agency, signed on 11th of October, 2016, the study is conducted by "Piejūra" with support from the European Regional Development Fund (ERDF) within the framework of the project "Latvian Food Industry Competence Centre".

\section{References}

1. Bimbo, A.P. (1989). Fish Oils: Past and Present food uses. Journal of the Americam Oil Chemists Society. 66(12): 1717-1726.

2. Bimbo, A.P., \& Crowther, J.B. (1992). Fish meal and oil: current uses. Journal of the American Oil Chemists Society, 69(3), pp. 221-227.

3. Brezeski, M.M. (1987). Chitin and chitosan: putting waste to good use. INFOFISH International (5), 31-33.

4. Devi, L., Aparna, N., \& Kalpana, K. (2013). Utilization of fish mince in formulation and development of pasta products. International Food Research Journal, 20(1), 219-224.

5. FAO (2014). The state of world fisheries and aquaculture. Food and Agriculture Organization of the United Nations, Rome.

6. FAO (2017). Global Capture Production database. Food and Agriculture Organization of the United Nations, Rome.

7. Gildberg, A. (1993). Enzymic processing of marine raw materials. Process Biochemistry, 28(1), pp. 1-15.

8. Jackson, A.J., Kerr, A.K., \& Cowey, C.B. (1984). Fish silage as a dietary ingredient for salmon. I. Nutritional and storage characteristics. Aquaculture, 38(3), pp. 211-220.

9. Lundqvist, J., de Fraiture, C., \& Molden, D. (2008). Saving water: from field to fork: curbing losses and wastage in the food chain. Stockholm: Stockholm International Water Institute.

10. Mackie, I.M. (1983). New Approaches in the Use of Fish Proteins". In Developments in Food Proteins, Edited by: Hudson, B.J.F. 215-262. London: Applied Science Publishers Ltd. 
11. Miles, R.D., \& Chapman, F.A. (2006). The benefits of fish meal in aquaculture diets. IFAS Extension, University of Florida.

12. Mulye, V., Zofair, M., Baraiya, S., Solanki, K., Chudasama, J., \& Temkar, S. (2014). Extrusion technology: Adding value to fish products. INFOFISH International 6/2014

13. Parfitt, J., Barthel, M., \& Macnaughton, S. (2010). Food waste within food supply chains: quantification and potential for change to 2050. Philosophical Transactions of the Royal Society B: Biological Sciences, 365(1554), 3065-3081.

14. Pimentel, D., \& Pimentel, M. (2003). Sustainability of meat-based and plant-based diets and the environment. The American journal of clinical nutrition, 78(3), pp. 660S-663S.

15. Regenstein, J.M. (2004). Total Utilisation of Fish. Food Technology. 58(3): 28-30.

16. Rustad, T. (2003). Utilisation of Marine By-products. Electronic Journal of Environmental, Agricultural and Food Chemistry, 2(4): 458-463.

17. Salin, V., Atkins, J.A., \& Salame, O. (2002). Value Added in Food Manufacturing and Retailing: A Ratio Analysis of Major US States. Journal of Food Distribution Research, 33(1), pp. 136-150.

18. Shahidi, F., \& Botta, J.R. (2012). Seafoods: chemistry, processing technology and quality. Springer Science \& Business Media.

19. Shahidi, F. (1994). Proteins from Seafood Processing Discards. In Seafood Proteins, Edited by: Sikorski, Z.E., Sun Pan, B. and Shahidi, F. 171-193. New York: Chapman and Hall.

20. Sharma, S., \& Basu, S. (2003). Preparation of an extruded fish snack using twin screw extruder and the storage characteristics of the product. Journal of the Indian Fisheries Association 30, 149-156.

21. Venugopal, V., Shahidi, F., \& Lee, T.C. (1995). Value-added products from underutilized fish species. Critical Reviews in Food Science \& Nutrition, 35(5), 431-453.

22. Wasswa, J., Tang, J., \& Gu, X. (2007). Utilization of fish processing by-products in the gelatin industry. Food Reviews International, 23(2), pp. 159-174. 